\title{
Los determinantes de los componentes del gasto electoral en elecciones municipales en Chile, 2008-2012
}

\author{
The determinants of different components of campaign \\ spending in municipal elections in Chile, 2008-2012 \\ PATRICIO DANIEL NAVIA LUCERO \\ New York University, Estados Unidos \\ Universidad Diego Portales, Chile \\ PAMELA ARANTXA ITURRA RODRIGUEZ \\ Universidad Diego Portales, Chile
}

RECEPCIÓN: 24/ 10/2016 • ACEPTACIÓN: 13/ 12/2016

RESUMEN Como en Chile hay información del tipo de gasto en que incurren los candidatos en campaña, pasamos de estudiar quién gasta más a analizar en qué gastan más los candidatos y qué determina sus tipos de gasto. Explicamos por qué los candidatos gastan de distinta forma sus fondos de campaña. Usamos información de los 54.276 ítems de gasto electoral reportados ante el Servicio Electoral por 2.390 candidatos a alcalde en las 345 comunas en 2008 y 2012. Con características sociodemográficas de las comunas, militancia, condición de incumbencia y género de los candidatos, evaluamos y explicamos las diferencias en los tipos de gasto. Contrario a lo que sugiere la literatura, los incumbentes chilenos gastan más en propaganda que los desafiantes. Aunque dedican más dinero a propaganda que los de la Concertación, los candidatos de derecha, en particular de la UDI, dedican un porcentaje menor de su gasto a propaganda. Las

1. Assistant Clinical Professor, Liberal Studies, New York University. Profesor titular de ciencia política, Universidad Diego Portales Correo: patricio.navia@nyu.edu

2. Cientista política de la Universidad Diego Portales.Actualmente trabaja en el SERVEL.Correo: pameiturra@gmail.com 
mujeres gastan más que los hombres y destinan un porcentaje menor a propaganda. Los candidatos en comunas con más ruralidad y mayor pobreza gastan menos en propaganda y más en desplazamientos y servicios. En comunas con más escolaridad, los candidatos gastan más en servicios.

PALABRAS CLAVE Gasto electoral - Componentes del gasto - Propaganda Incumbentes - Desafiantes.

ABSTRACT As there is information on the type of campaign spending in Chile, we can study not just who spends more but also what candidates spend on and what determines campaign expenditures. We explain what accounts for different types of spending. With information on 54,276 different campaign spending items reported by 2,390 mayoral candidates in 345 municipalities in 2008 and 2012 and using party membership, incumbency condition, gender of candidates and socio-demographic data at the municipal level, we differences on different types of expenditure. Contrary to what the literature suggests, incumbents spend more than challengers on advertising. Though they spend more on advertisement than Concertación candidates, rightwing candidates- especially those from the UDI-commit a lower share of their spending to advertisement. On average, women spend less than men and also spend less on advertisement. Candidates in poorer and rural municipalities spend less in advertisement and more on transportation and services. In municipalities with higher education, candidates spend more on services.

KEYWORDS Campaign spending - Types of campaing spending - Campaign advertising - Incumbents - challengers. 


\section{Los determinantes de los componentes del gasto electoral en elecciones municipales en Chile, 2008-2012}

En Chile a partir de la promulgación la Ley Sobre Transparencia, Límite y Control del Gasto Electoral (№19.884) en 2003, los candidatos deben transparentar sus aportes y gastos en campañas, lo que permite distinguir entre distintos componentes del gasto en que incurren. Trabajos anteriores han propuesto que el gasto electoral importa, pero poco se ha dicho de cómo los candidatos distribuyen sus recursos en los 9 distintos tipos de gasto que especifica la ley y qué explica por qué los candidatos gastan en lo que gastan.

Desde 2004, cuando hay datos públicos de gasto en campaña en Chile, distintos estudios han evaluado la validez de hipótesis existentes en la literatura para el caso chileno. La mayor parte de ellos se ordenan en torno a dos enfoques, el financiamiento de las campañas Agostini (2012); Fuentes (2005) y Johnson (2011) y el gasto de los candidatos. Los trabajos se han focalizado más en elecciones legislativas que en elecciones municipales ${ }^{4}$. Además, casi todos se enfocan en el efecto del gasto en el éxito electoral de los candidatos (gasto como variable independiente). Nosotros contribuimos a este creciente campo al evaluar los determinantes de los distintos componentes del gasto en que incurren los candidatos.

\section{Gasto electoral versus gasto en campaña}

En sus campañas electorales, los candidatos incurren en gastos, ya sea para hacer publicidad, para buscar asesoría de profesionales, o simplemente para hospedarse o desplazarse. Si bien hay muchos estudios que analizan el efecto de los gastos, es lógico presumir que distintos componentes del gasto tendrán efectos diferenciados sobre el desempeño electoral de un candidato.

Ansolabehere y Gerber analizan el efecto del gasto electoral en elecciones al congreso en Estados Unidos Ansolabehere y Gerber (1994). Utilizan sólo los estados donde la ley obliga a los candidatos a diferenciar entre tipos de gasto electoral. Los autores diferencian entre gasto electoral-el total de gastos

3. Agostini (2012); Fuentes (2005) y Johnson (2011)

4. Morales y Piñeiro (20109; Díaz et al. (2006); Urcullo y Moya (2009), Acevedo y Navia (2015), González (2015), Díaz et al. (2006).

5. Ansolabehere y Gerber (1994) 
incurridos por los candidatos-del gasto en campaña (el gasto utilizados por candidatos para fortalecer su figura). Utilizando solamente los gastos en campaña, reportan que la capacidad explicativa del gasto aumenta significativamente al explicar el éxito electoral. Los desafiantes gastan más de la mitad de su dinero en campaña (58\%), mientras que los incumbentes gastan sólo un $42 \%$.

Jacobson diferencia entre el gasto efectuado por los incumbentes y desafiantes. Si bien no se refiere precisamente a los tipos de gasto, se puede inferir que el tipo de gasto en el que incurren los candidatos varía si estos son incumbentes o desafiantes ${ }^{6}$. Edwards et al y Morales y Piñeiro señalan que el gasto es utilizado por incumbentes como una herramienta para promocionar su obra, mientras que los desafiantes gastan para hacerse conocidos ${ }^{7}$. Cuando hay información sobre el tipo de gasto de cada candidato, se puede asociar el tipo de gasto a diferentes funciones o efectos en la campaña. Para elaborar hipótesis que permitan evaluar el efecto de distintos tipos de gasto sobre el resultado electoral, primero revisaremos el estado del debate sobre las relaciones de causalidad entre el gasto en general y los resultados electorales.

\section{Gasto como variable independiente y dependiente}

El estudio del gasto electoral se divide en dos vertientes: como variable independiente para explicar el éxito de los candidatos o como variable dependiente, para identificar los determinantes del gasto. En la primera vertiente, Jacobson propone que el gasto de los desafiantes rinde más que el de los incumbentes y que el gasto en campaña es importante para candidatos que se tienen que dar a conocer8. En cambio, para candidatos conocidos, el efecto del dinero en las votaciones es muy bajo. Abramowitz añade que, al iniciar su campaña, los desafiantes deben darse a conocer incurriendo en un mayor gasto ${ }^{9}$. De hecho, el gasto en campaña es la variable que más explica la votación de los desafiantes en Estados Unidos. En la misma línea, Benoit y Marsh argumentan que el gasto de los desafiantes es más eficiente que el de los incumbentes ${ }^{10}$.

6. Jacobson (1978)

7. Edwards et al (2012) y Morales y Piñeiro(2010)

8. Jacobson (1981, 1978, 1990 y 2015)

9. Abramowitz (1991)

10. Benoit y Marsh (2010) 
En cambio, Green y Krasno argumentan que aunque los incumbentes parten con más reconocimiento de nombre, no tienen asegurada la victoria. Es más fácil derrotar a un incumbente poco gastador que uno que gasta más. Green y Krasno argumentan que el dinero rinde más para los incumbentes, debido a que éstos son considerados "políticos de calidad"11. Hogan, al estudiar elecciones primarias en Estados Unidos, sostiene que en la mayoría de los estados, los incumbentes gastan más. Además, la condición de incumbencia es más importante para explicar el gasto que el número de contendientes, o la población del distrito ${ }^{12}$ Hogan (1999). Benoit y Marsh señalan que, si bien en algunos casos el gasto puede ser más efectivo para desafiantes y en otros para incumbentes, ${ }^{10}$ tienen mejores probabilidades de salir electo los candidatos que más gastan.

Para el caso de Chile, Morales y Piñeiro (2010) indican que el gasto efectuado por desafiantes e incumbentes tiene distintos efectos en elecciones de diputados. Mientras los desafiantes enfocan su campaña en promocionarse, los incumbentes se enfocan en difundir su gestión. El gasto tiene la propiedad de "multiplicar los atributos de los candidatos"13. En 2005, los diputados incumbentes gastaron más que los desafiantes. Sin embargo, hubo un mayor efecto del gasto en el desempeño electoral de los desafiantes. Edwards et al (2012) obtienen resultados similares para las elecciones de alcaldes de 2004 y 2008 al mostrar que la votación de los desafiantes es más sensible al gasto en comparación a la de los incumbentes. A similares conclusiones llega Rivera (2012) para elecciones de alcalde.

Buena parte de los estudios sobre el gasto como variable dependiente se enfocan en elecciones en Estados Unidos. Hogan destaca que en distritos en que la campaña es más larga, el gasto efectuado es mayor que en distritos con campañas más cortas ${ }^{12}$. Efecto que también es observado por Weinscheck y Holbrook en elecciones locales ${ }^{14}$. Salka ${ }^{15}$ y Weinschek y Holbrook ${ }^{14}$ dicen que la característica de incumbencia en los candidatos es un determinante para incurrir en un mayor gasto. Hogan en su trabajo sobre las diferencias de

11. Green y Krasno (1988 y 1990)

12. Hogan (1999)

13. Morales y Piñeiro (2010) p. 650.

14. Weinscheck Y Holbrook (2014)

15. Salka (2009) 
género como determinante de gasto, destaca que las mujeres incumbentes gastan menos cuando se enfrentan a desafiantes hombres, y viceversa. Hogan además de utilizar los grupos desafiantes e incumbentes, incluye en su modelo los openseat candidates-aquellos que no compiten contra un incumbente. Argumenta que no existen diferencias entre lo gastado por desafiantes y por open-seat candidates $^{16}$.

Otra variable comúnmente utilizada para buscar qué determina el gasto de los candidatos es el partido político al que pertenecen. McAdams y Johannes argumentan que, ceteris paribus, no existen grandes diferencias entre lo gastado por demócratas y republicanos en elecciones al congreso en Estados Unidos ${ }^{17}$. Sin embargo, existen diferencias en el gasto dependiendo del partido oficialista del distrito por el que se compite. Es decir, cuando un demócrata busca el cargo en un distrito ocupado por un republicano, éste tiende a gastar más que su contendiente y viceversa. Hogan (2007), Weinschek y Holbrook y Salka no encuentran que la variable partido político haya sido significante al explicar el gasto electoral14y15. Hogan agrega como variable explicativa el número de contendores en cada distrito. Los candidatos gastan en promedio 7.000 dólares más por cada oponente extra, siendo esta variable un fuerte determinante del gasto $^{16}$. Weinschek y Holbrook utilizan el salario del cargo como un incentivo para que los candidatos incurran en un mayor gasto en campaña. Destacan que en dichas alcaldías en donde el cargo tiene mayor valor, medido con el salario, los candidatos gastan más ${ }^{14}$.

En Chile, diversos trabajos analizan el efecto del partido político o coalición de los candidatos18. La coalición de derecha, Alianza, gasta más que la izquierdista Concertación. Edwards et al. señalan que los partidos más gastadores son la Unión Demócrata Independiente (UDI) y Renovación Nacional (RN), los dos partidos que forman la Alianza. En la Concertación, el Partido Demócrata Cristiano (PDC) es el más gastador. Tanto la UDI como RN mientras más gastan, más votos obtienen. Mientras que para el PDC, el gasto tiene un efecto ligeramente negativo. Si bien el gasto tiene un efecto positivo para ambas coaliciones, para la Alianza rinde más. Acevedo destaca que, en elecciones de diputados, ambas coaliciones aceleran su gasto cuando existe la posibilidad de doblaje en los distritos,

16. Hogan (2007 Y 1999)

17. Mcadams y Johannes (1987)

18. Acevedo (2014); Edwards et al. (2012); Rivera (2012); Morales y Piñeiro (2010) y Johnson (2011) 
es decir, cuando una de las coaliciones tiene la oportunidad de llevarse los dos escaños en disputa. Johnson advierte que para elecciones al congreso en Chile, la UDI y el PDC son los partidos más gastadores, e incluso destaca que en la competencia intra-lista el partido de los candidatos es un mejor predictor de gasto que la incumbencia.

Ya que la teoría tiende a centrarse sobre las diferencias de gasto entre incumbentes y desafiantes, la militancia de los candidatos, el género y las características de los distritos en que compiten, nosotros aplicaremos esas consideraciones a los distintos tipos de gasto electoral que, por ley, deben informar los candidatos en elecciones en Chile. Aprovechando que en Chile se reporta el gasto por distintos tipos, evaluaremos hasta qué grado las explicaciones que se dan para explicar los distintos patrones de gasto entre distintos tipos de candidatos varían dependiendo del tipo de gasto en el que se incurre.

\section{Hipótesis}

Formulamos cuatro hipótesis que buscan evaluar los determinantes de los distintos componentes del gasto en campaña. Nuestra Hipótesis 1 postula que incumbentes y desafiantes distribuyen su gasto de forma distinta. Los incumbentes gastan más que los desafiantes, pero los desafiantes invierten su gasto más en propaganda porque, a diferencia de los incumbentes, ellos no se benefician del reconocimiento de nombre. Nuestra Hipótesis 2 aborda las diferencias en el gasto de acuerdo a la militancia. Sugerimos que ya que los militantes de partidos de derecha gastan más, tienen más recursos disponibles para dedicar a propaganda, por lo que debiéramos esperar que su gasto en propaganda sea una proporción mayor de su gasto total que para los candidatos de partidos de la Concertación. Nuestra Hipótesis 3 evalúa los patrones de gasto de acuerdo al sexo del candidato. Ya que las mujeres en general tienen menos trayectoria electoral que los hombres, esperamos que su comportamiento se asemeje al de los desafiantes frente a los incumbentes. Por lo tanto, esperaríamos que las mujeres gasten menos dinero que los hombres pero que dediquen un porcentaje mayor de su gasto a propaganda.

Nuestra Hipótesis 4 sugiere que las condiciones sociodemográficas de las comunas inducen a distintas formas de distribución de gasto. Pero ya que no existe discusión teórica que nos permita anticipar qué tipo de comunas van a inducir a los candidatos a destinar su gasto a determinados ítems, solo 
plantearemos que la pobreza, la ruralidad y escolaridad debiesen tener un efecto significativo sobre el tipo de gasto en el que incurren los candidatos. Esta hipótesis tiene carácter exploratorio en tanto podemos articular argumentos que lleven a asociar un mayor gasto en propaganda y servicios tanto en zonas urbanas como rurales. En cambio, suponemos que el gasto en desplazamientos debiese constituir un porcentaje mayor del gasto en aquellos candidatos que compiten en comunas con alta ruralidad.

\section{Datos y variables}

Para evaluar estas hipótesis, usamos datos de 54.276 ítems de gasto electoral reportados ante el Servicio Electoral por 2.390 candidatos a alcalde en las 345 comunas en 2008 y 2012. De acuerdo a la ley, estos gastos se agrupan en 9 tipos diferentes.

Ahora bien, en las 345 comunas de Chile, el alcalde se elige por mayoría simple en distritos uninominales cada 4 años. Las elecciones municipales son regidas por la Ley 18.700 Sobre Votaciones Populares y Escrutinios, además, cada candidato debe seguir normas de límites y transparencia del gasto, las cuales son estipuladas en la Ley 19.884 sobre Transparencia, Límite y Control del Gasto Electoral de 2003 para regular una serie de aspectos sobre financiamiento y gasto electoral. La ley establece normativas que deben seguir los candidatos. Los candidatos a alcalde no pueden sobrepasar el límite de 3.000 UF más 0,3 UF por cada elector en la comuna. un indicador elaborado por el Instituto Nacional de Estadísticas que mide la inflación.

Los valores en UF permiten comparar el valor real de la moneda, en tanto la UF incorpora la inflación19. En una comuna pequeña como Tortel en donde no hay más de 500 electores, el límite de gasto electoral en 2012 es poco más de \$3 millones. En comunas como Puente Alto con más de 500 mil electores, el límite es superior a \$220 millones. En segundo lugar, la ley establece que los candidatos deben presentar su contabilidad electoral precisando el destino del gasto. Para esto se establecen 9 tipos de cuentas que se encuentran en la Tabla 1.

19. Para 2008 el Servel fijó los límites de gastos electoral el 5 de mayo de 2008, UF con un valor de $\$ 19.883,04$. En 2012 la UF es fijada con valor del 24 de abril, correspondiente a \$22.594,22. 
Tabla 1. Tipos de gasto en la legislación chilena

\begin{tabular}{|c|c|}
\hline Tipo de gasto & Descripción de la ley \\
\hline Propaganda & $\begin{array}{l}\text { Propaganda y publicidad dirigida a promover el voto para un } \\
\text { candidato, cualquiera sea el lugar, forma y medio que se utilice. }\end{array}$ \\
\hline Encuestas & $\begin{array}{l}\text { Encuestas sobre materias electorales o sociales que encarguen } \\
\text { candidatos o partidos políticos, durante la campaña. }\end{array}$ \\
\hline Arriendo de bienes & $\begin{array}{l}\text { Arrendamiento de bienes muebles e inmuebles destinados al } \\
\text { funcionamiento de los equipos de campaña o actos de proselitismo. }\end{array}$ \\
\hline Desplazamientos & $\begin{array}{l}\text { Gastos realizados para el desplazamiento de candidatos, dirigentes, } \\
\text { partidos y personas que presten servicios a las candidaturas, } \\
\text { como asimismo para transporte de implementos de propaganda } \\
\text { y la movilización de personas con motivo de actos de campaña. }\end{array}$ \\
\hline Servicios prestados & $\begin{array}{l}\text { Pagos por servicios que prestan personas (naturales o jurídicas) } \\
\text { a la campaña electoral. }\end{array}$ \\
\hline $\begin{array}{l}\text { Patrocinios y/ } 0 \\
\text { Donaciones }\end{array}$ & $\begin{array}{l}\text { Erogaciones o donaciones realizadas por candidatos a } \\
\text { organizaciones o a personas naturales o jurídicas, mediante el } \\
\text { patrocinio de actos culturales, deportivos o de cualquier otro tipo } \\
\text { dentro del ámbito territorial respectivo. }\end{array}$ \\
\hline Trabajos voluntarios & $\begin{array}{l}\text { Gastos por trabajos de campaña, proporcionados por personas } \\
\text { con carácter voluntario, debidamente avaluados de acuerdo a } \\
\text { criterios objetivos. }\end{array}$ \\
\hline $\begin{array}{l}\text { Intereses por } \\
\text { préstamo }\end{array}$ & $\begin{array}{l}\text { Costo de endosos e intereses, gastos notariales y gastos en que } \\
\text { haya incurrido por efecto de la obtención de créditos recibidos } \\
\text { para la campaña }\end{array}$ \\
\hline Gastos menores & $\begin{array}{l}\text { Gastos menores y frecuentes de campaña, tales como la } \\
\text { alimentación, mantención de vehículos o de sedes u otros similares. } \\
\text { Éstos podrán ser rendidos, sin justificación detallada, hasta por } \\
\text { el 10\% del límite total autorizado al candidato o partido político. }\end{array}$ \\
\hline
\end{tabular}

Fuente: Elaboración propia con datos de www.servel.cl

Las variables independientes se dividen en dos grupos. Primero, variables propias del candidato, incumbencia, militancia y género. Segundo, condiciones sociodemográficas de las comunas, que utilizamos como variables de control. Estos datos los obtuvimos del Sistema Nacional de Información Municipal del Gobierno de Chile (SINIM). La tabla 2 muestra un resumen de las variables independientes, incluyendo nombre, descripción, indicador o rango y fuente de cada una, y también de nuestras variables independientes-las que explicamos más abajo. 
Tabla 2. Variables independientes y de control

\begin{tabular}{|lll|}
\hline & Variables propias del candidato (Servel) \\
\hline Variable & \multicolumn{1}{c|}{ Descripción } & \multicolumn{1}{c|}{ Indicador } \\
Incumbencia & $\begin{array}{l}\text { Si el candidato es incumbente } \\
\text { o desafiante }\end{array}$ & $\begin{array}{l}0=\text { Desafiante } \\
1=\text { Incumbente }\end{array}$ \\
& Si el candidato & $0=$ Mujer \\
Género & es hombre o mujer & $1=$ Hombre \\
& & RN, UDI, DC, PS, PC, PPD, PRSD, \\
Afiliación & Partido del candidato, & PRO, PH, PRI, PI, MAS, \\
Partidaria & o si es independiente & PEV, IND (Dummies por partido) \\
& & $1=$ Alianza \\
& & $2=$ Concertación \\
Coalición & Coalición del candidato & \\
& & $4=$ Otra \\
& & \\
\end{tabular}

\begin{tabular}{|ccc|}
\hline \multicolumn{3}{|c|}{ Condiciones sociodemográficas de las comunas (SINIM) } \\
\hline Variable & \multicolumn{1}{c|}{ Descripción } & Rango \\
\hline Pobreza & \% población pobre por comuna & 0 a $51 \%$ \\
Ruralidad & \% población rural por comuna & 0 a $100 \%$ \\
Escolaridad & $\begin{array}{l}\text { Años de escolaridad } \\
\text { promedio por comuna }\end{array}$ & 4 a 15 años \\
\hline
\end{tabular}

Fuente: Elaboración propia con datos de www.servel.cl y www.sinim.cl

La Tabla 3 muestra los estadísticos descriptivos de las variables independientes que usamos en el análisis. Hay suficiente varianza en todas ellas para poder evaluar su efecto sobre los distintos componentes del gasto en campaña en 2008 y 2012. 
Tabla 3. Descriptivos de las variables independientes y dependientes

\begin{tabular}{|lccccc|}
\hline \multicolumn{1}{|c}{ Variable } & N & Min & Max & Med & $\begin{array}{c}\text { Desviación } \\
\text { Estándar }\end{array}$ \\
Pobreza \% & 2105 & 0 & 51 & 16,6 & 8,347 \\
Ruralidad \% & 2096 & 0 & 100 & 35,2 & 29,223 \\
\hline Escolaridad (\# años) & 2055 & 4 & 15 & 9,0 & 1,450 \\
$\begin{array}{l}\text { Incumbencia } \\
\text { (sí, no) }\end{array}$ & 2105 & 0 & 1 & 0,24 & 0,429 \\
$\begin{array}{l}\text { Género } \\
\text { (mujer, hombre) }\end{array}$ & 2105 & 0 & 1 & 0,84 & 0,366 \\
$\begin{array}{l}\text { Afiliación } \\
\text { partidaria (sí o no) }\end{array}$ & 2105 & 0 & 1 & 0,58 & 0,494 \\
$\begin{array}{l}\text { Coalición } \\
\text { Propaganda PorTC }\end{array}$ & 2105 & 1 & 4 & 2,32 & 1,167 \\
\hline Servicios PorTC & 2105 & 0 & 100 & 46,8 & 30,9 \\
\hline \begin{tabular}{l} 
Desplazamientos PorTC \\
\hline
\end{tabular} & 2105 & 0 & 100 & 18,5 & 21,7 \\
\hline
\end{tabular}

Fuente: Elaboración propia con datos de www.servel.cl y www.sinim.cl

La base de gasto de elecciones en 2008 y 2012 del Servicio Electoral 20 contiene información sobre los 1.231 candidatos a alcalde en 2012 y de los 1.159 en 2008 en las 345 comunas. Ahora bien, no todos los candidatos declaran su gasto en campañas. En 2008, 131 no declararon gastos, y otros 132 declararon no haber gastado. La Tabla 4 muestra el número de candidatos a alcalde en 2008 y 2012 de acuerdo a cómo reportaron su gasto en campaña. También identificamos a aquellos candidatos que gastaron sobre el $90 \%$ del límite permitido, número que bajó casi a la mitad entre 2008 y 2012, y a los que gastaron menos del $10 \%$ del límite permitido-el 23,9\% y 24,4\% en 2008 y 2012 respectivamente.

20. La base fue obtenida del sitio del Servicio Electoral:http:/ / www.servel.cl/ ss/ site/ documento/ detalle_ingresos_2012.xls 
Tabla 4. Candidatos a alcaldes de acuerdo a su gasto electoral, 2008 y 2012

\begin{tabular}{|lrrrrr|}
\hline Candidatos que... & $\mathbf{2 0 0 8}$ & $\mathbf{\%}$ & $\mathbf{2 0 1 2}$ & $\mathbf{\%}$ & \multicolumn{1}{c|}{ Total } \\
\hline \# & 1.231 & -- & 1.159 & -- & 2.390 \\
No declaran gasto & 131 & -- & 138 & -- & 269 \\
Declaran gasto $\$ 0$ & 16 & & 0 & & 16 \\
Declararon gasto sobre \$0 & $\mathbf{1 . 0 8 6}$ & $\mathbf{1 0 0}$ & $\mathbf{1 . 0 2 1}$ & $\mathbf{1 0 0}$ & $\mathbf{2 . 1 0 5}$ \\
Sobrepasan el límite de gasto & 36 & 3,3 & 26 & 2,5 & 62 \\
Declaran gasto entre 90 y 100\% del límite & 83 & 7,5 & 44 & 4,3 & 127 \\
\hline Declaran entre el 10 y el 90\% del límite & 704 & 64,8 & 754 & 73,9 & 1.404 \\
Declaran gastar entre 0 y 10\% del límite & 263 & 23,9 & 249 & 24,4 & 512 \\
\hline
\end{tabular}

Fuente: Elaboración propia con datos de Servel.

La base de datos del Servel contiene 54.276 ítems de gasto de 2.105 candidatos. De ellos, 28.514 corresponden a 1.084 candidatos en 2008 y 25.762 ítems de 1.021 candidatos en 2012. En la base de Servel, cada ítem es clasificado de acuerdo a una de las 9 categorías de gasto estipulados en la ley. En 2008, hay un promedio de 26,3 ítems declarado por candidato y en 2012 el promedio de ítems declarado fue de 25,2.

La base incluye una serie de gastos que han sido erróneamente clasificados de acuerdo a las 9 categorías. Por ejemplo, en 2012 en Calbuco, el candidato UDI Paulino Díaz, declaró como gasto en propaganda la compra de una impresora y combustible, siendo que estos gastos debieron ser declarados como gastos menores y desplazamientos. Por eso, revisamos cada uno de los 54.276 ítems de gasto. En todos los casos de gasto mal clasificado, reclasificamos de acuerdo a lo que corresponde a partir de la descripción del gasto incurrido en cada ítem. La Tabla 5 muestra la clasificación original de los distintos ítems en la base de Servel y la clasificación depurada en la base que utilizamos para este estudio. Como queda evidencia, el número total de ítems no varió, pero su clasificación de acuerdo al tipo de gasto sí varío marginalmente. El depurar la base presentada por el Servicio Electoral, nos permitió conocer en que realmente gastan los candidatos, y a la vez saber qué porcentaje su gasto invierten en cada tipo de gasto electoral. A partir de esto hemos creado el índice gasto por total del candidato Gasto PorTC, que nos permite saber qué porcentaje del gasto efectuado, invierte cada candidato en los tipos de propaganda, variable que explicaremos a partir de las variables independientes, anteriormente mencionadas. Cabe destacar que existen 
diversos índices de gasto electoral, Acevedo y Navia realizan un estudio de los índices para medir gasto electoral, concluyen que al medir el total de gasto (no por ítems como se realiza en este trabajo) el mejor indicar es el Gasto en relación al límite de gasto permitido en el respectivo territorio electoral ${ }^{21}$

Para ejemplificar los componentes del gasto, usamos dos ejemplos de la elección de 2012. El alcalde independiente por la Alianza, Sergio Zarzar, reportó \$80.884.264 de gasto en Chillán, el más alto en su comuna (83\% del máximo permitido). Su gasto en propaganda y asesorías llegó a 64 millones. Su más cercano rival, Aldo Bernucci (PRSD), gastó sólo \$38.442.542 (39\% del máximo permitido), principalmente en arriendos y gastos menores. Zarzar obtuvo el 43,6\%, mientras que Bernucci llegó a 39\%. En Alto del Carmen, la alcaldesa independiente Nora Rojas, reportó un gasto de $\$ 661.472$, correspondiente al 11\% del límite permitido, fundamentalmente en desplazamientos y gastos menores. Su principal desafiante, Carmen Bou Bou, invirtió \$2.615.160, principalmente en propaganda y trabajos voluntarios. Entre 6 candidatos, Bou Bou ganó con un 26,2\% y la incumbente quedó en tercer lugar con 12\%.

Tabla 5. Descripción de los ítems de gasto en la base de datos de Servel y en la base depurada utilizada en este estudio, 2008-2012

\begin{tabular}{|l|r|r|r|r|r|r|}
\hline & \multicolumn{2}{|c|}{ Numero de ítems de gasto en 2008 } & \multicolumn{2}{c|}{ Numero de ítems de gasto en 2012 } \\
\hline \multicolumn{1}{|c|}{ Ítems } & $\begin{array}{c}\text { Cuenta } \\
\text { original } \\
\text { Servel }\end{array}$ & $\begin{array}{c}\text { Cuenta } \\
\text { depurada }\end{array}$ & $\begin{array}{c}\text { Monto } \\
\text { máximode } \\
\text { gasto en un } \\
\text { ítem } \mathbf{\$ M M}\end{array}$ & $\begin{array}{c}\text { Cuenta } \\
\text { original } \\
\text { Servel }\end{array}$ & $\begin{array}{c}\text { Cuenta } \\
\text { depurada }\end{array}$ & $\begin{array}{c}\text { Monto } \\
\text { máximode } \\
\text { gasto en un } \\
\text { ítem \$MM* }\end{array}$ \\
\hline Gastos Menores & 6.947 & 7.126 & 9,1 & 7.749 & 7.394 & 22,8 \\
\hline Desplazamiento & 6.494 & 8.160 & 13,4 & 6.284 & 7.392 & 15,2 \\
\hline Propaganda & 6.522 & 6.730 & 24,0 & 6.304 & 7.110 & 45,7 \\
\hline Trabajos voluntarios & 1.378 & 2.217 & 17,3 & 1.150 & 1.679 & 26,0 \\
\hline Servicios & 3.228 & 2.128 & 11,1 & 2.480 & 1.342 & 59,5 \\
\hline Arriendos & 1.038 & 658 & 28,5 & 902 & 437 & 20,0 \\
\hline Donaciones & 1.264 & 1.295 & 3,3 & 707 & 304 & 10,0 \\
\hline Encuestas & 42 & 50 & 5,2 & 43 & 38 & 8,7 \\
\hline Intereses por préstamo & 33 & 34 & 2,1 & 33 & 35 & 6,7 \\
\hline Exceso de Aporte Público & 33 & 34 & 2,1 & 4 & 14 & 2,0 \\
\hline No definido & 13 & 13 & 26,7 & 102 & 13 & 1,2 \\
\hline Exceso de Aporte Reservado & 10 & 17 & 1,2 & 4 & 4 & 28,6 \\
\hline Total general de ítems & $\mathbf{2 8 . 5 1 4}$ & $\mathbf{2 8 . 5 1 4}$ & & $\mathbf{2 5 . 7 6 2}$ & $\mathbf{2 5 . 7 6 2}$ & \\
\hline \# candidatos & 1.084 & 1.084 & & 1.021 & 1.021 & \\
\hline
\end{tabular}

21. Acevedo y Navia (2015)

Fuente: autores con datos de Servel. *En cuenta depurada. 
Ya que en 2012 entró en vigencia el sistema de inscripción automática y voto voluntario, hubiera sido razonable esperar que se modificara el patrón de gasto respecto a 2008. Sin embargo, pese que el padrón de inscritos aumentó en casi 5 millones de personas aproximadamente, ni el número de candidatos ni el nivel de gasto variaron de manera significativa.

La Tabla 6 muestra la suma y promedio de gastos en UF. Los mayores gastos son en propaganda, servicios y desplazamientos. Con un gasto bastante menor, se encuentran los gastos menores y trabajos voluntarios. Los gastos en encuestas, exceso aporte público y privado, intereses por préstamo, gastos no definidos y donaciones son montos casi insignificantes. En vista de los montos de gasto realizado por los candidatos, utilizaremos los 3 gastos más utilizados por los candidatos, propaganda, desplazamientos y servicios, el resto de los gastos los agruparemos en la categoría otros gastos.

El promedio de gasto respecto al máximo permitido en cada comuna fue de $42,1 \%$ en 2008y35,5\% en 2012.La disminución se explica por hadopción del sistema deinscripción automática que hizo que el padrón electoral pasara de 8 a 13 millones de personas en el periodo. Como el límite de gasto se define a partir de bs electores inscritos para votar, todas las comunas vieron aumentar el límite de gasto permitido entre 2008 y 2012. En 2008, el $20 \%$ de bs candidatos que menos declaró tiene un promedio de gasto de $4,5 \%$ y el $20 \%$ que más gastó un 100,6\% respecto al límite. En 2012, el 20\% de bs candidatos que menos gastó tiene un promedio de gasto de 1,1\% del gasto respecto al límite, el 20\% de los candidatos que más gastó tiene un promedio de 87,8\% respecto al límite.

Tabla 6. Suma y promedio de gastos en UF de los 2105 candidatos a alcaldes en 2008 y 2012

\begin{tabular}{|lrrr|}
\hline Tipo de cuenta & Suma de gastos en UF & Promedio de gastos en UF & \% del total de gastos \\
Arriendo & $28.452,8$ & 13,5 & 3,6 \\
Desplazamiento & $119.126,6$ & 56,6 & 15,3 \\
\hline Encuestas & $7.201,1$ & 3,4 & 0,9 \\
Exceso \$ público & 580,5 & 0,3 & 0,1 \\
Exceso \$ reservado & $3.977,8$ & 1,9 & 0,5 \\
Gastos menores & $79.488,6$ & 37,8 & 10,2 \\
Intereses por préstamo & $1.470,5$ & 0,7 & 0,2 \\
No definidos & 388,7 & 0,2 & 0,1 \\
\hline Donaciones & $6.689,6$ & 3,2 & 0,9 \\
Propaganda & $456.677,6$ & 216,9 & 58,6 \\
Servicios prestados & $124.421,0$ & 59,1 & 16,0 \\
Trabajos voluntarios & $47.767,4$ & 22,7 & 6,1 \\
\hline Total general & $876.242,0$ & 370,0 & 100,0 \\
\hline
\end{tabular}

Fuente: Elaboración propia con datos de www.servel.cl 


\section{Análisis inferencial}

Para evaluar las hipótesis, utilizamos el gasto como porcentaje del total reportado por cada candidato (PorTC). Ya que usamos los valores en UF, estamos incorporando la inflación, por lo que los datos de 2008 y 2012 son comparables. Con todo, buscamos explicar si los distintos tipos de candidatos distribuyen su gasto de forma diferente. Así, por ejemplo, si en 2008 el gasto en propaganda fue un 55\% y en 2012 fue de un 45\%, hubo más gasto relativo en propaganda en 2008 queen 2012.Al usar PorTC, controlamos por las distintas cantidades de gasto de los candidatos. Así, si un candidato gastó 100 millones de pesos, pero dedicó la mitad de ese dinero a propagada, su gasto en propaganda será igual al de un candidato que, habiendo gastado en total 4 millones de pesos, dedicó 2 millones a propaganda.

\section{Hipótesis 1: Incumbentes y desafiantes}

En 2008, hubo 270 incumbentes y 961 desafiantes. El 78\% de los alcaldes se presentó a la reelección y 173 fueron reelectos. En 2012, 288 alcaldes se presentaron a la reelección, 172 ganaron. Aquí evaluamos el efecto de la condición de incumbencia sobre el tipo de gasto en el que incurren los candidatos.

En cada comuna puede haber un incumbente y en general hay varios desafiantes. Algunos desafiantes tienen pocas chances de ganar. Luego, pudiera ser razonable considerar solo a los desafiantes de las dos principales coaliciones. Pero ya que en promedio un $11,5 \%$ de las comunas tienen alcaldes independientes, no podemos discriminar a priori excluyendo a los independientes del análisis. (11\% en 2008 y $12 \%$ en 2012 )

La Tabla 7 muestra el promedio de gasto para incumbentes y desafiantes, y el promedio de gasto PorTC. Si bien los desafiantes gastaron más que los incumbentes, hubo tres veces más desafiantes que incumbentes. Al evaluar el gasto per cápita, los incumbentes en promedio gastaron un total de 609 UF mientras que los desafiantes gastaron solo $354 \mathrm{UF}$. Al evaluar el gasto per cápita, los incumbentes gastan más del doble que los desafiantes en propaganda. Esto contradice lo que sugiere nuestra primera hipótesis-y lo que en general postula la teoría, que los desafiantes gastan más que los incumbentes en buscar hacerse conocidos.

21. Acevedo y Navia (2015) 
Cuando medimos cada ítem de gasto como porcentaje del gasto total de cada candidato (PorTC), los incumbentes también invierten más que los desafiantes en propaganda. Los incumbentes no sólo gastan más per cápita en propaganda que los desafiantes sino que también gastan una proporción mayor de su gasto total en propaganda ( $54 \%$ versus $44 \%$ ). En desplazamientos no existen diferencias entro lo gastado por ambos grupos. En servicios y en otros gastos, los desafiantes invierten más de su dinero que los incumbentes.

Tabla 7. Promedio de gasto PorTCy en UF, incumbentes y desafiantes, 2008-2012

\begin{tabular}{|lcccc|}
\hline Item & Incumbentes & Desafiantes & $\begin{array}{c}\text { Incumbentes } \\
\text { ganadores }\end{array}$ & $\begin{array}{c}\text { Desafiantes } \\
\text { ganadores }\end{array}$ \\
Propaganda & $54,4 \%^{* *}$ & $44,4 \%^{* *}$ & $55,7 \% * *$ & $47,6 \% * *$ \\
Servicios & $10,3 \%^{*}$ & $14,0 \%^{*}$ & $9,9 \%^{*}$ & $12,6 \% *$ \\
Desplazamientos & $18,9 \%^{* *}$ & $18,3 \%^{* *}$ & $18,7 \%$ & $18,6 \%$ \\
Otros & $16,3 \%$ & $23,3 \%$ & $15,7 \%$ & $21,2 \%$ \\
Total & $100 \%$ & $100 \%$ & $100 \%$ & $100 \%$ \\
& & Promedio en UF & \\
Propaganda & $354,6^{* *}$ & $172,9 * *$ & 408,2 & 351,6 \\
Servicios & $69,5^{*}$ & $55,8^{*}$ & 77,5 & 93,4 \\
Desplazamientos & 77,3 & 50,0 & 84,4 & 81,8 \\
Otros & 108,0 & 75,8 & 113,0 & 118,2 \\
Total & 609,4 & 354,5 & 683,2 & 645,0 \\
\hline \# candidatos & $\mathbf{5 1 0}$ & $\mathbf{1 . 5 9 5}$ & $\mathbf{3 2 5}$ & $\mathbf{3 1 4}$ \\
\hline
\end{tabular}

**significativo al 0.001 *significativo al 0.05 . Niveles de significancia se miden horizontalmente entre columnas relevantes. Incumbentes vs desafiantes, e incumbentes ganadores versus desafiantes ganadores. Se excluye para medición de "otros".

Fuente: Elaboración propia con datos del Servel

Mientras los desafiantes invierten una considerable suma de dinero en desplazamientos, encuestas y donaciones, los incumbentes gastan la mayor parte de su dinero en propaganda. Esta contradicción con lo que reporta la literatura pudiera explicarse porque los incumbentes conocen mejor las estrategias de campañas y el efecto que tiene la propaganda en relación a las otros gastos de campaña. Pero como no hay razón para pensar que los desafiantes en Chile sean menos informados que los desafiantes de otros países que gastan más en propaganda que los incumbentes, bien pudiera ser que las aseveraciones que se hacen sobre el tipo de gasto en otros países simplemente no se condiga con la 
realidad de cómo se distribuye el gasto en campaña, hecho que nos permite testear únicamente en Chile y la obligación de declarar en distintos tipos de gasto.

Podemos validar parcialmente la Hipótesis 1. Hay diferencias en la forma en que incumbentes y desafiantes distribuyen su gasto. Pero a diferencia de lo que esperábamos, los incumbentes gastan más que los desafiantes en propaganda, tanto en valor absoluto como en porcentaje de su gasto total.

\section{Hipótesis 2: Militancia. Partido y coalición}

En el periodo, la coalición centro-izquierdista experimentó algunos cambios. En 2008, el PC realizó un pacto por omisión con la Concertación, pero fue formalmente parte de la lista Juntos Podemos Más, junto al Partido Humanista. En 2012 el PC volvió a realizar un pacto por omisión con la Concertación. Por esa razón, incluimos al Partido Comunista como miembro de la Concertación (pero no a los otros partidos que fueron parte de la coalición que lideraba el PC en 2008 y 2012 y que con posterioridad no siguieron el camino del PC de formalmente unirse al pacto de centro-izquierda).

El partido político de los candidatos ha sido comúnmente señalado como una variable que explica el gasto. Pero como discutimos anteriormente, en Estados Unidos no se ha reportado gran diferencia entre lo gastado por demócratas y republicanos. En Chile, los trabajos sí muestran diferencias entre lo gastado por candidatos de diferentes partidos y coaliciones. Pero los estudios sobre Chile en general cubren elecciones de diputados, las cuales hasta 2013 se realizaban bajo un sistema electoral proporcional binominal. En este sistema, la posibilidad de resultar electo dependía tanto de la votación individual como de la votación que obtuvieran en conjunto los dos candidatos de cada lista. Así, el efecto del gasto de cada candidato explicaba solo parcialmente su posibilidad de resultar electo. En cambio, en elecciones de alcalde, cada lista puede presentar solo un candidato. El gasto del candidato influye directamente sobre su posibilidad de victoria.

Por cierto, la Ley 19.884 otorga a los partidos un anticipo fisca. El anticipo fiscal se otorga en base a la votación que obtuvieron en las elecciones de igual naturaleza anterior. Los partidos que no participaron en la elección anterior, se le otorga un monto igual al partido que obtuvo la menor votación. Los partidos reciben como anticipo un equivalente a la mitad de lo que les correspondería si 
repiten el número de votos de la elección anterior. Los partidos pueden decidir si ese dinero lo asignan a sus candidatos o si lo utilizan de modo centralizado para la campaña respectiva.

La tabla 8 muestra el número de candidatos por partido y coalición en 2008 y 2012. La Concertación presentó el mayor número de candidatos. En esa coalición, el PDC fue el partido con más candidatos. Los dos partidos de la Alianza, la UDI (129) y RN (121) ocupan el segundo y tercer lugar en número de candidatos. El número de independientes fuera de pacto fue de 577 , superando en número a cada uno de los partidos. También existe un número importante de candidatos independientes dentro de los pactos. En el análisis, distinguimos entre distintos tipos de independiente (dentro o fuera de pacto).

Tabla 8. Número de candidatos por partido y coalición, 2008-2012

\begin{tabular}{|c|c|c|c|c|}
\hline Coalición o Partido & 2008 & 2012 & Total & $\%$ \\
\hline Alianza & 312 & 316 & 628 & 29,8 \\
\hline Renovación Nacional (RN) & 111 & 110 & 221 & 10,5 \\
\hline Unión Demócrata Independiente (UDI) & 124 & 126 & 250 & 11,9 \\
\hline Independientes en pacto & 77 & 80 & 157 & 7,5 \\
\hline Concertación & 441 & 317 & 758 & 36,0 \\
\hline Movimiento Amplio Social (MAS) & 0 & 7 & 7 & 0,3 \\
\hline Partido Comunista de Chile(PC) & 75 & 7 & 82 & 3,9 \\
\hline Partido Demócrata Cristiano (PDC) & 111 & 117 & 228 & 10,8 \\
\hline Partido por la Democracia(PPD) & 64 & 57 & 121 & 5,8 \\
\hline Partido Radical Socialdemócrata (PRSD) & 11 & 27 & 38 & 1,8 \\
\hline Partido Socialista de Chile(PS) & 70 & 62 & 132 & 6,3 \\
\hline Independientes en alguno de bs pactos & 96 & 54 & 150 & 7,1 \\
\hline Otras coalicionesy partidos & 60 & 82 & 142 & 6,8 \\
\hline Partido Humanista(PH) & 30 & 21 & 51 & 2,4 \\
\hline Partido Igualdad (PI) & 0 & 1 & 1 & 0,05 \\
\hline Partido Regionalista de bs Independientes (PRI) & 30 & 26 & 56 & 2,7 \\
\hline Partido Progresista (PRO) & 0 & 34 & 34 & 1,6 \\
\hline Independientes fuera de pacto & 271 & 306 & 577 & 27,4 \\
\hline Total general & 1.084 & 1.021 & 2.105 & 100 \\
\hline
\end{tabular}

Fuente: Elaboración propia con datos del Servel

La mayor cantidad de alcaldes electos en Chile pertenece a una de las coaliciones mayoritarias, la Alianza y la Concertación. Trabajos previos han reportado 
que los candidatos de la Alianza gastan más en campaña (Edwards et al., 2012). Aquí agrupamos a los candidatos en cuatro categorías, Alianza, Concertación, otras coaliciones e independientes fuera de pacto.

La Tabla 9 muestra el promedio de gasto por coalición en UF y el promedio de gasto PorTC. La Alianza gastó más en promedio por cada candidato, 296 UF por candidato versus 263 UF por candidatos de la Concertación. El gasto de los candidatos de otras coaliciones y de independientes fuera de pacto fue sustancialmente menor.

Los candidatos de la Concertación enfocan el 80\% de su gasto en 3 ítems, propaganda (51\%), servicios (12\%) y desplazamientos (18\%). Aunque tiene un gasto promedio mayor que la Concertación, la Alianza invierte casi el mismo porcentaje combinado (77\%) en los tres ítems, pero gasta menos en propaganda (42\%) y más en servicios (14\%) y desplazamientos (21\%). Si bien los candidatos de la Concertación gastan un porcentaje mayor de su gasto total en propaganda, en términos del gasto promedio por candidato, los candidatos de la Alianza gastan más que los de la Concertación. Aunque los candidatos de otras coaliciones y los independientes gastan mucho menos que los de la Alianza y Concertación, distribuyen su gasto de forma similar que los candidatos de las dos coaliciones más grandes.

Tabla 9. Promedio de gasto PorTCy en UF, por coaliciones, 2008-2012

\begin{tabular}{|lcccc|}
\hline Item & Alianza & Concertación & $\begin{array}{c}\text { Otras } \\
\text { coaliciones }\end{array}$ & $\begin{array}{c}\text { Independientes } \\
\text { fuera de pacto }\end{array}$ \\
Propaganda & $42 \% * *$ & Promedio por TC \\
Servicios & $14 \% *$ & $51 \% * *$ & $45 \% * *$ & $47 \% * *$ \\
Desplazamientos & $21 \% * *$ & $12 \% *$ & $22 \% *$ & $12 \% *$ \\
Otros & $23 \%$ & $18 \% * *$ & $13 \%$ & $18 \%$ \\
Total & $100 \%$ & $20 \%$ & $19 \%$ & $23 \%$ \\
& & $100 \%$ & $100 \%$ & $100 \%$ \\
Propaganda & 296,4 & Promedio en UF & \\
Servicios & $94,3 * *$ & 263,6 & 50,0 & 110,3 \\
Desplazamientos & $93,9 * *$ & $60,6 * *$ & 22,8 & 27,9 \\
Otros & 139,8 & $56,7 * *$ & 12,1 & 26,7 \\
Total & 624,3 & 80,3 & 20,7 & 42,4 \\
\hline \# candidatos & $\mathbf{6 2 8}$ & 461,2 & 105,6 & 207,3 \\
\hline
\end{tabular}

**significativo al 0.001 *significativo al 0.05. Niveles de significancia se miden horizontalmente entre Concertación y Alianza. Se excluye para medición de "otros".

Fuente: Elaboración propia 
Otros estudios han mostrado que la UDI es el partido más gastador en la Alianza $^{22}$. Aquí mostramos que la UDI también gasta más en elecciones de alcaldes, En las dos contiendas, la Alianza presentó 628 candidatos, de los cuales 250 eran UDI, 221 RNy 157 independientes. La Tabla 10 muestra el promedio en UFy el gasto PorTC de los candidatos de los partidos de la Alianza. Los candidatos UDI tienen un gasto promedio de casi el doble que los de RN e independientes Alianza. Al analizar el gasto PorTC, tanto RN como la UDI invierten un $75 \%$ de su gasto en los 3 ítems principales (propaganda, desplazamientos y servicios), mientras que los de $\mathrm{RN}$ dedican casi un $80 \%$ de su gasto a esos tres ítems. Con todo, ya que los candidatos UDI gastan en promedio más que los RN o independientes Alianza, en promedio el gasto por cada ítem es superior en la UDI, aunque esa diferencia es mayor en desplazamientos y propaganda y menor en servicios.

Tabla 10. Promedio de gasto PorTC y en UF,partidos Alianza, 2008-2012

\begin{tabular}{|lccc|}
\hline Item & UDI & RN & IND y otros \\
Propaganda & \multicolumn{3}{c|}{ Promedio por TC } \\
Servicios & $38,6 \% *$ & $44,1 \% *$ & $45,2 \%$ \\
Desplazamientos & $12,2 \%$ & $15,8 \%$ & $14,2 \%$ \\
Otros & $24,2 \% *$ & $19,6 \% *$ & $18,1 \%$ \\
Total & $24,9 \%$ & $20,5 \%$ & $22,5 \%$ \\
& $100 \%$ & $100 \%$ & $100 \%$ \\
Propaganda & \multicolumn{3}{c}{} \\
Servicios & $396,7 *$ & Promedio en UF & 234,4 \\
Desplazamientos & 113,1 & 79,8 & 84,7 \\
Otros & $141,6 * *$ & $63,5 * *$ & 60,7 \\
Total & 203,4 & 90,1 & 108,5 \\
\hline \# candidatos & 854,8 & 460,2 & 488,4 \\
\hline
\end{tabular}

**significativo al 0.001 *significativo al 0.05. Niveles de significancia se miden horizontalmente entre UDI y RN. Se excluye para medición de "otros".

Fuente: Elaboración propia. 
Estudios anteriores han mostrado que el partido más gastador en la Concertación es el PDC. La Tabla 11 muestra el promedio en UF del y el promedio PorTC de los candidatos de la Concertación. El PDC es el partido que más gasta, seguido del PS. Ambos gastan cuatro veces más en promedio que el PC. Los candidatos del PDC invierten un mayor porcentaje de su gasto en propaganda $(55,7 \%)$, seguido por candidatos del PS y PRSD. El PC en cambio dedica un porcentaje sustancialmente menor de su gasto $(36,8 \%)$ a propaganda.

Tabla 11. Promedio de gasto PorTCy en UF, partidos Concertación, 2008-2012

\begin{tabular}{|c|c|c|c|c|c|c|}
\hline Item & PC & PDC & PPS & PRSD & PS & IND y otros \\
\hline \multicolumn{7}{|c|}{ Promedio por TC } \\
\hline Propaganda & $36,8 \%$ & $55,7 \%$ & $51,3 \%$ & $52,9 \%$ & $53,4 \%$ & $48,5 \%$ \\
\hline Servicios & $10,0 \%$ & $10,7 \%$ & $10,9 \%$ & $11,6 \%$ & $11,5 \%$ & $13,5 \%$ \\
\hline Desplazamientos & $15,3 \%$ & $18,4 \%$ & $20,7 \%$ & $21,2 \%$ & $16,8 \%$ & $16,0 \%$ \\
\hline Otros & $37,9 \%$ & $15,2 \%$ & $17,1 \%$ & $14,3 \%$ & $18,2 \%$ & $22,0 \%$ \\
\hline Total & $100 \%$ & $100 \%$ & $100 \%$ & $100 \%$ & $100 \%$ & $100 \%$ \\
\hline \multicolumn{7}{|c|}{ Promedio en UF } \\
\hline Propaganda & 82,2 & 370,1 & 281,3 & 260,9 & 346,7 & 120,5 \\
\hline Servicios & 10,8 & 89,3 & 59,8 & 57,4 & 70,8 & 36,3 \\
\hline Desplazamientos & 19,7 & 67,2 & 67,8 & 73,4 & 74,1 & 35,0 \\
\hline Otros & 53,9 & 91,2 & 85,7 & 92,2 & 109,1 & 48,8 \\
\hline Total & 166,6 & 617,8 & 494,5 & 483,9 & 600,7 & 240,6 \\
\hline \# candidatos & 82 & 228 & 121 & 38 & 132 & 150 \\
\hline
\end{tabular}

Fuente: Elaboración propia.

Existen altas diferencias entre las coaliciones en su gasto total de campaña y en la forma como distribuyen ese gasto. También hay diferencias entre los partidos de cada coalición tanto en el total de sus gastos como en la forma en que lo distribuyen. En general, los candidatos de otras coaliciones y los independientes gastan menos que los candidatos de las dos principales coaliciones, pero distribuyen su gasto de forma similar. Hay más diferencias entre partidos tanto en la cantidad de sus gastos como en la forma en que lo distribuyen.

Los candidatos de partidos de derecha gastan más que los de los partidos de la Concertación. Pero el gasto total promedio en propaganda se mueve en rangos similares entre los partidos de la Alianza y la Concertación. Ahora bien, y tal vez porque el gasto total de los candidatos de derecha es superior, el porcentaje de su gasto que dedican a propaganda es menor que el de los candidatos de la 
Concertación. Si suponemos que la necesidad de gastar en propaganda obliga a candidatos de distintas coaliciones a incurrir en similares cantidades de dinero para dedicar a ese ítem, entonces los candidatos de la derecha quedan con dinero adicional que pueden dedicar a otros tipos de gasto y que, en el total, hace ver que su porcentaje de gasto en propaganda es menor. Por ejemplo, los candidatos de la UDI en promedio, y también en propaganda, gastan más que los candidatos de cualquier otro partido. Pero como tienen más dinero para gastar, el porcentaje de su gasto total que dedican a la propaganda es menor que lo que se observa en candidatos de otros partidos.

Nuestra hipótesis 2 sugería que, dado que tienen más recursos para gastar, los candidatos de derecha dedican un porcentaje mayor de su gasto a propaganda que los candidatos de otros partidos. Pero la evidencia nos lleva a rechazar dicha hipótesis. Aunque dedican más dinero a propaganda que los candidatos de la Concertación, los candidatos de derecha, en particular los de la UDI, dedican un porcentaje menor de su gasto total a propaganda. Esto parece indicar que el gasto total en propaganda tiende a aumentar de forma no lineal e incluso pudiera tener un techo. Aquellos candidatos que cuentan con más recursos gastan más dinero en propaganda, pero mientras más dinero tienen, menor es el porcentaje de su gasto total que destinan a propaganda. Al menos eso es lo que se puede deducir a partir de lo que se observa para la UDI, el partido cuyos candidatos más gastan en promedio.

\section{Hipótesis 3: Género}

Evaluamos también si hay diferencias entre hombres y mujeres en los tipos de gasto en los que incurren como candidatos. Si bien la mayoría de los candidatos son hombres, hay un número suficiente de mujeres para poder realizar este análisis. En promedio, las mujeres fueron el 16\% de los candidatos (177 en 2008 y 158 en 2012).

La Tabla 12 muestra el promedio de gasto en UF por ítems y el promedio PorTC para candidatas y candidatos en 2008 y 2012. En promedio, las mujeres gastan más de un 10\% por sobre los hombres en su gasto total, pero su gasto en propaganda es sólo marginalmente superior al de los hombres. Más aun, como porcentaje de su gasto, las mujeres destinan menos a propaganda que los hombres. 
Nuestra Hipótesis 3 sugiere que las mujeres se deberían comportar como los desafiantes frente a incumbentes y que, por lo tanto, gastarán más y dedicarán un mayor porcentaje de su gasto a la propaganda. Anteriormente, mostramos que los desafiantes gastan menos que los incumbentes y dedican un porcentaje menor de su gasto a propaganda. La Tabla 12 muestra, en cambio, que las mujeres gastan de la misma forma que la teoría sugiere se deben comportar los incumbentes, no los desafiantes. Las mujeres gastan más que los hombres en promedio y tienden a destinar un porcentaje menor de su gasto a propaganda. Luego, rechazamos nuestra Hipótesis 3.

Tabla 12. Promedio de gasto PorTCy en UF, por género, 2008-2012

\begin{tabular}{|c|c|c|}
\hline Item & Mujeres & Hombres \\
\hline \multicolumn{3}{|c|}{ Promedio por TC } \\
\hline Propaganda & $43,4 \% *$ & $47,4 \% *$ \\
\hline Servicios & $14,5 \%$ & $12,8 \%$ \\
\hline Desplazamientos & $18,6 \%$ & $18,5 \%$ \\
\hline Otros & $23,6 \%$ & $21,3 \%$ \\
\hline Total & $100 \%$ & $100 \%$ \\
\hline \multicolumn{3}{|c|}{ Promedio en UF } \\
\hline Propaganda & 229,6 & 214,5 \\
\hline Servicios & 65,8 & 57,8 \\
\hline Desplazamientos & 65,9 & 54,8 \\
\hline Otros & 106,7 & 79,2 \\
\hline Total & 468,0 & 406,5 \\
\hline \# candidatos & 335 & 1770 \\
\hline
\end{tabular}

**significativo al 0.001 *significativo al 0.05. Niveles de significancia se miden horizontalmente entre Mujeres y Hombres. Se excluye para medición de "otros".

Fuente: Elaboración propia

\section{Hipótesis 4: Condiciones sociodemográficas de las comunas}

En este apartado analizamos si los factores sociodemográficos de las comunas influyen en el nivel de gasto de los candidatos y en el tipo de gasto en que incurren. También incluimos las variables analizadas anteriormente para evaluar el efecto de cada una de ellas controlando por el efecto de las otras. 
Utilizamos 3 variables sociodemográficas a nivel comunal, el porcentaje de población rural, los años de escolaridad promedio y el porcentaje de pobreza. Además, usamos tres variables dummy que indican el sexo (hombre) del candidato, la incumbencia y si el candidato milita en algún partido. Identificamos si los candidatos militan en partidos de la Concertación o Alianza-lo que convierte a los candidatos que militan en cualquier otra coalición en una variable de referencia-y si militan en alguno de los siete partidos más importantes de ambas coaliciones ( 2 de la Alianza y 5 de la Concertación) - lo que automáticamente convierte a los candidatos que militan en cualquier otro partido de cualquier coalición y los independientes en categoría de referencia. Presentamos regresiones lineales multivariadas usando como variable dependiente el gasto en tres ítems distintos, propaganda, desplazamiento y servicios.

Con cada ítem de gasto presentamos cuatro modelos. El primero incluye sólo las variables sociodemográficas. El segundo agrega atributos propios del candidato, como sexo, incumbencia y militancia. El tercer modelo incluye las variables dummy Concertación y Alianza- pero excluye la variable de militancia. El cuarto modelo incluye variables dummy que identifican a militantes de los 7 partidos más importantes, y por lo tanto excluye las coaliciones y el dummy de militancia.

En la Tabla 13, la variable dependiente es el porcentaje del gasto total del candidato (PorTC) que se destina a propaganda. En bs 4 modelos, el gasto en propaganda como porcentaje del total de gasto fue superior en 2012 que en 2008. El gasto en propaganda también es superior en comunas con mayor ruralidad y en comunas con mayor pobreza, aunque la significancia estadística es menor.

En los tres modelos relevantes, los hombres gastan más en propaganda que las mujeres. Los incumbentes también gastan más que los desafiantes. En dos de los tres modelos, los militantes gastan menos que los desafiantes. Los candidatos de la Alianza gastan menos en propaganda y los de la Concertación gastan más. Como porcentaje total de su gasto, los militantes UDI y PC gastan menos en propaganda, mientras que los del PDC, PRSD y PS gastan más.

Como este modelo analiza el gasto en propaganda como porcentaje del gasto total, controlando simultáneamente por otras variables, podemos confiadamente sugerir que el gasto en propaganda tiende a ser mayor en zonas rurales y en comunas con más pobreza. Por cierto, también estimamos el efecto de densidad poblacional por comuna, pero los resultados no son significativos ni contribuyen a 
REVISTA CHILENA DE DERECHO Y CIENCIA POLÍTICA SEPTIEMBRE - DICIEMBRE 2016 •ISSN 0718-9389 • e-ISSN 0719-2150 • VOL. 7 • $\mathrm{N}^{\circ} 3$

DOI 10.7770/RCHDYCP-V7N3-ART1155

mejorar la capacidad predictiva del modelo (ni de los modelos posteriores).

Tabla 13. Regresión lineal sobre gasto en propaganda (PorTC) por candidato, 2008-2012

\begin{tabular}{|c|c|c|c|c|}
\hline & Modelo 1 & Modelo 2 & Modelo 3 & Modelo 4 \\
\hline $\begin{array}{l}\text { Año } \\
(2008=0 ; 2012=1)\end{array}$ & $\begin{array}{c}1,405^{* *} \\
(, 339)\end{array}$ & $\begin{array}{c}1,251^{* *} \\
(, 335)\end{array}$ & $\begin{array}{c}1,315^{* *} \\
(, 335)\end{array}$ & $\begin{array}{c}1,149 * * \\
(, 337)\end{array}$ \\
\hline Ruralidad & $\begin{array}{c}-, 155^{* *} \\
(, 038)\end{array}$ & $\begin{array}{l}-, 162^{* *} \\
(, 037)\end{array}$ & $\begin{array}{l}-, 142 * * \\
(, 035)\end{array}$ & $\begin{array}{l}-, 152 * * \\
(, 035)\end{array}$ \\
\hline Escolaridad & $\begin{array}{l}-, 367 \\
(, 830)\end{array}$ & $\begin{array}{l}-, 227 \\
(, 820)\end{array}$ & $\begin{array}{l}-, 208 \\
(, 735)\end{array}$ & $\begin{array}{l}-, 123 \\
(, 732)\end{array}$ \\
\hline Pobreza & $\begin{array}{l}-, 100 \\
(, 098)\end{array}$ & $\begin{array}{l}-, 105^{* *} \\
(, 097)\end{array}$ & $\begin{array}{l}-, 007 \\
(, 087)\end{array}$ & $\begin{array}{l}-, 023 \\
(, 087)\end{array}$ \\
\hline $\begin{array}{l}\text { Dummy sexo } \\
\text { candidato } M=0 ; H=1\end{array}$ & & $\begin{array}{l}3,866 * * \\
(1,819)\end{array}$ & $\begin{array}{l}3,455^{* *} \\
(1,817)\end{array}$ & $\begin{array}{l}3,258 * * \\
(1,812)\end{array}$ \\
\hline $\begin{array}{l}\text { Dummy incumbencia } \\
\text { Inc }=1 \text {; Desa }=0\end{array}$ & & $\begin{array}{c}11,504^{* *} \\
(1,610)\end{array}$ & $\begin{array}{c}11,014^{* *} \\
(1,634)\end{array}$ & $\begin{array}{c}10,351 * * \\
(1,668)\end{array}$ \\
\hline $\begin{array}{l}\text { Dummy militancia } \\
\text { Milita }=1 ; \text { No milita }=0\end{array}$ & & $\begin{array}{c}-2,463^{* *} \\
(1,392)\end{array}$ & & \\
\hline Dummy Alianza & & & $\begin{array}{c}-6,137 * * \\
(1,710)\end{array}$ & \\
\hline Dummy Concertación & & & $\begin{array}{c}1,632 \\
(1.663)\end{array}$ & \\
\hline UDI & & & & $\begin{array}{c}-10,190 * * \\
(2,188)\end{array}$ \\
\hline $\mathrm{RN}$ & & & & $\begin{array}{l}-3,698 \\
(3,225)\end{array}$ \\
\hline PDC & & & & $\begin{array}{l}6,211 * * \\
(3,239)\end{array}$ \\
\hline PPD & & & & $\begin{array}{c}2,056 \\
(2,971)\end{array}$ \\
\hline PRSD & & & & $\begin{array}{c}4,128 \\
(4,985)\end{array}$ \\
\hline PS & & & & $\begin{array}{c}3,308 \\
(2,883)\end{array}$ \\
\hline PC & & & & $\begin{array}{l}-8,370 \\
(3,448)\end{array}$ \\
\hline Constante & $\begin{array}{c}-2766,107^{* *} \\
(679,676)\end{array}$ & $\begin{array}{c}-2463,442^{* *} \\
(672,246)\end{array}$ & $\begin{array}{c}-2597,743^{* *} \\
(673,079)\end{array}$ & $\begin{array}{c}-2261,850 * * \\
(675349)\end{array}$ \\
\hline F & 14,281 & 16,533 & 15,659 & 12,526 \\
\hline R cuadrado &, 027 &, 054 &, 063 &, 074 \\
\hline R cuadrado ajustado &, 025 &, 050 &, 059 & 068 \\
\hline $\mathrm{N}$ & 2105 & 2105 & 2105 & 2105 \\
\hline
\end{tabular}

**Significativo al 0.05. Realizamos los tests de multicolinealidad sin encontrar evidencia. Fuente: Elaboración propia con datos de www.servel.cl y www.sinim.cl 
En la Tabla 14, la variable dependiente es el porcentaje del gasto total del candidato (PorTC) que se destina a desplazamientos. En los 4 modelos, a diferencia del análisis en propaganda, el gasto fue superior en 2008 que en 2012. En estos modelos, hay mayor gasto en desplazamientos por parte de los candidatos en comunas con mayor ruralidad y pobreza. En comunas con más escolaridad, los candidatos gastan menos en desplazamientos. La condición de incumbencia sólo resultó significativa en el modelo 4, indicando que incumbentes gastan más en desplazamientos. Las variables dummy de Alianza y Concertación mostraron que los candidatos de la Alianza tienen una inversión de gasto superior en desplazamiento. Por último los candidatos UDI, RNy PPD muestran una mayor inversión de gasto en desplazamiento. A partir de la evidencia de la Tabla 14, podemos aseverar que el gasto en desplazamientos es superior en comunas con mayor ruralidad y pobreza y menor en comunas con mayor escolaridad. 
Tabla 14. Regresión lineal sobre gasto en desplazamientos (PorTC) por candidato, 2008-2012

\begin{tabular}{|c|c|c|c|c|}
\hline & Modelo 1 & Modelo 2 & Modelo 3 & Modelo 4 \\
\hline $\begin{array}{l}\text { Año } \\
(2008=0 ; 2012=1)\end{array}$ & $\begin{array}{l}-, 170 \\
(, 235)\end{array}$ & $\begin{array}{l}-, 149 \\
(, 235)\end{array}$ & $\begin{array}{l}-, 131 \\
(, 237)\end{array}$ & $\begin{array}{l}-, 156 \\
(, 238)\end{array}$ \\
\hline Ruralidad & $\begin{array}{l}, 182^{* *} \\
(, 026)\end{array}$ & $\begin{array}{l}, 182 * * \\
(, 026)\end{array}$ & $\begin{array}{l}, 161^{* *} \\
(, 025)\end{array}$ & $\begin{array}{l}, 161 * * \\
(, 025)\end{array}$ \\
\hline Escolaridad & $\begin{array}{c}-1,297 * * \\
(, 575)\end{array}$ & $\begin{array}{c}-1,325^{* *} \\
(, 576)\end{array}$ & $\begin{array}{c}-1939 * * \\
(, 518)\end{array}$ & $\begin{array}{c}-1,935^{* *} \\
(, 517)\end{array}$ \\
\hline Pobreza & $\begin{array}{l}, 185^{* *} \\
(, 068)\end{array}$ & $\begin{array}{l}, 188^{* *} \\
(, 068)\end{array}$ & $\begin{array}{c}, 072 \\
(, 061)\end{array}$ & $\begin{array}{c}, 085 \\
(, 061)\end{array}$ \\
\hline $\begin{array}{l}\text { Dummy sexo } \\
\text { candidato } \mathrm{M}=0 ; \mathrm{H}=1\end{array}$ & & $\begin{array}{c}-, 408 \\
(1,276)\end{array}$ & $\begin{array}{c}-, 148 \\
(1,282)\end{array}$ & $\begin{array}{c}-, 023 \\
(1,281)\end{array}$ \\
\hline $\begin{array}{l}\text { Dummy incumbencia } \\
\text { Inc }=1 \text {; Desa }=0\end{array}$ & & $\begin{array}{c}1,313 \\
(1,130)\end{array}$ & $\begin{array}{l}-1,136 \\
(1,153)\end{array}$ & $\begin{array}{c}-1,992 * * \\
(1,179)\end{array}$ \\
\hline $\begin{array}{l}\text { Dummy militancia } \\
\text { Milita }=1 \text {; No milita }=0\end{array}$ & & $\begin{array}{c}1,500^{* *} \\
(, 977)\end{array}$ & & \\
\hline Dummy Alianza & & - & $\begin{array}{l}2,817^{* *} \\
(1,206)\end{array}$ & - \\
\hline Dummy Concertación & & - & $\begin{array}{c}0,187 \\
(1,173)\end{array}$ & - \\
\hline UDI & & & & $\begin{array}{l}6,823^{* *} \\
(1,547)\end{array}$ \\
\hline $\mathrm{RN}$ & & & & $\begin{array}{l}1,581 \text { ** } \\
(1,597)\end{array}$ \\
\hline PDC & & & & $\begin{array}{c}1,193 \\
(1,610)\end{array}$ \\
\hline PPD & & & & $\begin{array}{l}2,708^{* *} \\
(2,101)\end{array}$ \\
\hline PRSD & & & & $\begin{array}{c}2,443 \\
(3,525)\end{array}$ \\
\hline PS & & & & $\begin{array}{c}0,527 \\
(2,038)\end{array}$ \\
\hline PC & & & & $\begin{array}{l}-1,340 \\
(2,438)\end{array}$ \\
\hline Constante & $\begin{array}{l}362,655^{* *} \\
(470,886)\end{array}$ & $\begin{array}{l}319,884^{* *} \\
(471,846)\end{array}$ & $\begin{array}{c}292,525 \\
(474,735)\end{array}$ & $\begin{array}{l}386,468^{* *} \\
(477,163)\end{array}$ \\
\hline $\mathrm{F}$ & 59,321 & 34,340 & 27,469 & 18,743 \\
\hline R cuadrado & 104 & ,105 & ,105 &, 111 \\
\hline R cuadrado ajustado & 104 & , 102 & ,102 & 106 \\
\hline $\mathrm{N}$ & 2105 & 2105 & 2105 & 2105 \\
\hline
\end{tabular}

**Significativo al $0.05 \%$. Realizamos los tests de multicolinealidad sin encontrar evidencia.

Fuente: Elaboración propia con datos de www.servel.cl y www.sinim.cl 
En la Tabla 15, la variable dependiente es el porcentaje del gasto total que el candidato destina a servicios (asesorías). El gasto en servicios es superior solo en comunas con mayor escolaridad. El coeficiente negativo de la incumbencia indica que, en los 3 modelos, los desafiantes gastan más en servicios que los incumbentes. Hay un mayor gasto en servicios entre los militantes. El gasto en servicios es inferior para los militantes de todos los partidos y de la Concertación (la variable Alianza no resulto significativa). A diferencia de los gastos realizados en propaganda y desplazamientos, el gasto en servicios es mayor en comunas con mayor escolaridad. 
Tabla 15. Regresión lineal sobre gasto en servicios (PorTC) por candidato, 2008-2012

\begin{tabular}{|c|c|c|c|c|}
\hline & Modelo 1 & Modelo 2 & Modelo 3 & Modelo 4 \\
\hline $\begin{array}{l}\text { Año } \\
(2008=0 ; 2012=1)\end{array}$ & $\begin{array}{l}-, 266 \\
(, 241)\end{array}$ & $\begin{array}{l}-, 212 \\
(, 241)\end{array}$ & $\begin{array}{l}-, 259 \\
(, 242)\end{array}$ & $\begin{array}{l}-, 304 \\
(, 244)\end{array}$ \\
\hline Ruralidad & $\begin{array}{l}, 020 \\
(, 027)\end{array}$ & $\begin{array}{l}, 022 \\
(, 027)\end{array}$ & $\begin{array}{l}, 025 \\
(, 025)\end{array}$ & $\begin{array}{l}, 023 \\
(, 026)\end{array}$ \\
\hline Escolaridad & $\begin{array}{l}2,513 * * \\
(, 590)\end{array}$ & $\begin{array}{c}2,461 * * \\
(, 590)\end{array}$ & $\begin{array}{c}2,666 * * \\
(, 531)\end{array}$ & $\begin{array}{c}2,638 * * \\
(, 531)\end{array}$ \\
\hline Pobreza & $\begin{array}{l}-.051 \\
(, 070)\end{array}$ & $\begin{array}{l}-, 047 \\
(, 070)\end{array}$ & $\begin{array}{l}-, 046 \\
(, 070)\end{array}$ & $\begin{array}{l}-, 010 \\
(, 063)\end{array}$ \\
\hline $\begin{array}{l}\text { Dummy sexo } \\
\text { candidato } \mathrm{M}=0 ; \mathrm{H}=1\end{array}$ & & $\begin{array}{l}-1,460 \\
(1,308)\end{array}$ & $\begin{array}{l}-1,382 \\
(1,312)\end{array}$ & $\begin{array}{l}-1,508 \\
(1,314)\end{array}$ \\
\hline $\begin{array}{l}\text { Dummy incumbencia } \\
\text { Inc }=1 \text {; Desa }=0\end{array}$ & & $\begin{array}{c}-3,746^{* *} \\
(1,158)\end{array}$ & $\begin{array}{c}-3,214^{* *} \\
(1,180)\end{array}$ & $\begin{array}{c}-2,956^{* *} \\
(1,209)\end{array}$ \\
\hline $\begin{array}{l}\text { Dummy militancia } \\
\text { Milita }=1 \text {; No milita=0 }\end{array}$ & & $\begin{array}{l}1,828^{* *} \\
(1,001)\end{array}$ & & \\
\hline Dummy Alianza & & & $\begin{array}{c}1,560 \\
(1,234)\end{array}$ & \\
\hline Dummy Concertación & & & $\begin{array}{l}-1,200 \\
(1,369)\end{array}$ & \\
\hline UDI & & & & $\begin{array}{l}-0,617 \\
(1,587)\end{array}$ \\
\hline $\mathrm{RN}$ & & & & $\begin{array}{c}-3,213^{* *} \\
(1,637)\end{array}$ \\
\hline PDC & & & & $\begin{array}{l}-2,114 \\
(1,640)\end{array}$ \\
\hline PPD & & & & $\begin{array}{l}-1,435 \\
(2,154)\end{array}$ \\
\hline PRSD & & & & $\begin{array}{l}-0,308 \\
(3,615)\end{array}$ \\
\hline PS & & & & $\begin{array}{l}-1,486 \\
(2,090)\end{array}$ \\
\hline PC & & & & $\begin{array}{l}-4,341 \\
(2,500)\end{array}$ \\
\hline Constante & $\begin{array}{c}524,493 \\
(483,589)\end{array}$ & $\begin{array}{c}418,777 \\
(483,404)\end{array}$ & $\begin{array}{c}510,879 \\
(486,110)\end{array}$ & $\begin{array}{l}602,339 * * \\
(487,818)\end{array}$ \\
\hline $\mathrm{F}$ & 13,008 & 9,327 & 7,946 & 6,798 \\
\hline R cuadrado &, 025 & 031 &, 032 &, 034 \\
\hline R cuadrado ajustado &, 023 & 028 & ,028 &, 028 \\
\hline $\mathrm{N}$ & 2105 & 2105 & 2105 & 2105 \\
\hline
\end{tabular}

**Significativo al $0.05 \%$. Realizamos los tests de multicolinealidad sin encontrar evidencia.

Fuente: Elaboración propia con datos de www.servel.cl y www.sinim.cl 
Finalmente, la Tabla 16 presenta un consolidado con el signo de todas las variables estadísticamente significativas que explican los distintos tipos de gasto. Como nuestra cuarta hipótesis asocia el tipo de gasto a las características sociodemográficas de las comunas, la Tabla 16 nos permite verificar la existencia de una relación entre ruralidad, escolaridad y pobreza y los tres tipos de gasto. Los candidatos en comunas con más ruralidad gastan menos en propaganda y más en desplazamientos, lo que parece razonable, dado que la densidad poblacional es menor en zonas rurales. Los candidatos gastan más en servicios y en menos en desplazamiento en comunas con más escolaridad, lo que parece razonable en tanto las comunas con más educación tienden a presentar desafíos más complejos para candidatos que buscan diseminar mensajes de campaña. Los candidatos también gastan menos en propaganda y más en servicios en comunas con más pobreza.

Tabla 16. Consolidado de significancia estadísticas de variables independientes sobre distintos tipos de gasto PorTC por candidato, 2008-2012

\begin{tabular}{|c|c|c|c|}
\hline Variables independientes & $\begin{array}{c}\text { Gastos en } \\
\text { propaganda }\end{array}$ & $\begin{array}{c}\text { Gastos en } \\
\text { Desplazamiento }\end{array}$ & $\begin{array}{l}\text { Gastos en } \\
\text { Servicios }\end{array}$ \\
\hline Año (2012) & $+1+$ & & + \\
\hline Ruralidad & --- & $+1+$ & \\
\hline Escolaridad & & --- & $+1++$ \\
\hline Pobreza & --- & $+1+$ & \\
\hline $\begin{array}{l}\text { Dummy sexo } \\
\text { candidato } \mathrm{M}=0 ; \mathrm{H}=1\end{array}$ & $+H$ & & \\
\hline Dummy incumbencia & $+H$ & + & -- \\
\hline Dummy militancia & -- & + & ++ \\
\hline Dummy Alianza & - & + & \\
\hline Dummy Concertación & + & & - \\
\hline UDI & - & + & - \\
\hline $\mathrm{RN}$ & & + & - \\
\hline PDC & + & & - \\
\hline PPD & & + & - \\
\hline PRSD & + & & - \\
\hline PS & + & & - \\
\hline $\mathrm{PC}$ & - & & - \\
\hline
\end{tabular}

Fuente: autores con datos de los cuadros 13-15. 


\section{Conclusiones}

Si bien hay extensa literatura sobre los efectos del gasto en el desempeño electoral de incumbentes y desafiantes, hay bastante menos conocimientos sobre los tipos de gasto en los que incurren los candidatos. Aquí describimos los distintos tipos de gasto que se tipifican en la legislación vigente en Chile y exploramos algunos determinantes que dan cuenta de por qué los candidatos distribuyen de distinta forma sus recursos de campaña en elecciones municipales.

Con datos de los componentes del gasto en campaña en elecciones municipales en 2008 y 2012 en Chile, evaluamos 4 hipótesis sobre los determinantes del tipo de gasto. Mostramos que, contrario a lo que se espera, los incumbentes gastan más en propaganda que los desafiantes. Si bien la literatura siguiere que los desafiantes gastan más para darse a conocer, los alcaldes que buscan la re-elección en Chile gastan más que sus rivales, pese a ser más ya más conocidos.

Mostramos que los candidatos de la Alianza gastan más que los de la Concertación, pero invierten un porcentaje menor de su gasto en propaganda. Los candidatos de la Concertación dedican un porcentaje mayor de su gasto a servicios. Los candidatos independientes y de otras coaliciones invierten en propaganda un porcentaje mayor de su gasto. Las mujeres invierten un porcentaje menor de su gasto en propaganda. Finalmente, reportamos que los candidatos en comunas con niveles más altos de educación gastan menos en desplazamientos y más en servicios, mientras que los candidatos en zonas rurales y en comunas con más pobreza gastan más en desplazamiento y menos en propaganda.

De las 4 hipótesis planteadas 3 han sido rechazadas, derribando al mismo tiempo teorías que la literatura ha dado por hecho no solo en Chile, sino que en estudios internacionales sobre gasto electoral. Uno de los descubrimientos más relevantes es el hecho de que incumbentes gasten más en propaganda, mientras otros estudios daban por hecho que desafiantes gastaban más en propaganda, este estudio demuestra que los incumbentes son quienes más gastan, no solo en total de gasto, sino que en el gasto del total del candidato, esto nos indica que independiente de la capacidad para obtener dinero y gastarlo, lo que realmente importa es como los candidatos pueden gastar sus recursos disponibles einvertirlos de manera efectiva durante la campaña electoral. 


\section{BIBLIOGRAFIA}

ABRAMOWITZ, Alan (1991): "Incumbency, campaign spending, and the decline of competition in US House elections". En The Journal of Politics, University of Chicago Press, vol. 53, n 1 , pp. 34-56.

ACEVEDO, Sergio y NAVIA, Patricio. (2015). “Un método no endógeno para medir el gasto electoral en Chile, 2005-2009”.En Revista mexicana de ciencias políticas y sociales, UNAM,vol. 60, n²25, pp. 103-131.

AgostinI, Claudio (2012): "Financiamiento de la política en Chile: Campañas electorales 2009-2010".En Díaz, Francisco y Sierra, Lucas (Eds.): Democracia con Partidos. Informe para la reforma de los partidos políticos en Chile (pp 269-319). (Santiago, CEP-CIEPLAN).

ANSOLABEHERE, Stephen. and GeRBER, Alan. (1994): "The mismeasure of campaign spending: Evidence from the 1990 US House elections”. En The Journal of Politics, University of Chicago Press, vol. 56, n ${ }^{\circ}$, pp. 1106-1118.

BENOIT, Kenneth y MARSH, Michael. (2010): "Incumbent and challenger campaign spending effects in proportional electoral systems the Irish elections of 2002". En Political Research Quarterly, university of Utah, vol. 63, n 1 , pp. 159-173. DíAZ, Diego, GIANNINI, Pilar, LuNA, Juan Pablo, \& NúÑEZ, R. (2006): “El secreto de mi éxito: Seis caminos para llegar y permanecer en Valparaíso". En Revista de ciencia política, PUC, vol. 26, n 1, pp.169-190.

EdWARDS, Santiago; MoRALES, Mauricio y SCHUSTER, Martín (2012): ¿El dinero hace la felicidad?. Efecto del gasto en campaña sobre el desempeño electoral de los candidatos a alcalde en Chile, 2004-2008. En: Morales, Mauricio y Navia, Patricio (2012): Democracia Municipal en Chile, 1992-2012 (Santiago, Ediciones UDP).

FUENTES, Claudio (2005): Dinero y Elecciones en Chile. Lecciones de las municipales 2004. Observatorio №7. Flacso. Chile.

GARRETÓN, Manuel Antonio y GARRETÓN, Roberto. (2010): “La democracia incompleta en Chile: La realidad tras los rankings internacionales".En Revista de ciencia política, PUC,vol. 30, n 1 , pp. 115-148.

GONZÁLEZ-BUSTAMANTE, Bastian. (2015): "Éxito electoral y gasto en campañas en las elecciones de senadores y diputados en Chile 2013”. En Revista Políticas Públicas, USACH, vol. 8, n 1 , pp. 21-35.

GREEN, Donald. and KRASNO, Jonathan. (1988): "Salvation for the Spendthrift Incumbent: Reestimating the Effects of Campaign Spending in House Elections". En American Journal of Political Science,Michigan State University, vol. 32, n 4, pp. 884-890. GREEN, Donald. and KRASNO, Jonathan. (1990): "Rebuttal to Jacobson's New Evidence for Old Arguments". En American Journal of Political Science, Michigan State University , vol.34, $n^{\circ} 2$, pp. 363-372. 
HogAN, Robert. (1999): “Campaign Spending in State Legislative Primary Elections”. En State

\& Local Government Review, University of Georgia, vol. 31, n 3, pp. 214-220. HOGAN, Robert. (2000): "The Costs of Representation in State Legislatures: Explaining Variations in Campaign Spending". EnÊSocial Science Quarterly,Willey-Blackwell, vol. 81, n 4 , pp.941-956.

Hogan, Robert. (2007): "The Effects of Candidate Gender on Campaign Spending in State Legislative Elections". En Social Science Quarterly, Willey-Blackwell, vol. 88, n 5, pp. 1092-1105.

HoGAN, Robert. (2013): Campaign spending and voter participation in state legislative elections. En Social Science Quarterly, Willey-Blackwell, vol. 94, n³ 3p. 840-864. JACOBSON, Gary. (1978): "The effects of campaign spending in congressional elections". En American Political Science Review, Cambridge University Press, vol. 72, n 02, pp. 469-491.

JACOBSON, Gary. (1981): "Incumbents' Advantages in the 1978 U. S. Congressional Elections". En Legislative Studies Quarterly, Washington University, vol.6, n² 2, pp. 183-200.

JACOBSON, Gary. (1990): "The Effects of Campaign Spending in House Elections: New Evidence for Old Arguments". En American Journal of Political Science, Michigan State University, vol. 34, n² 2, pp. 334-362.

JACOBSON, Gary. (2015): “How Do Campaigns Matter?” En Annual Review Political Science, University of California, San Diego, 2015, Vol. 18:1-499,

JoHNSON, Joel (2011): "Incumbents without a Campaign Finance Advantage: Competition and Money in Chile's Congressional Elections". En Journal of Politics in Latin America, Hamburg University Press, vol. 3, n 3, pp. 3-33.

MORALES, Mauricio y PIÑEIRO, Rafael. (2010): "Gasto en campaña y éxito electoral de los candidatos a diputados en Chile 2005". En Revista de ciencia política, PUC, vol. 30, n³, pp. 645-667.

MCADAMS, John and JoHANNES, John. (1987): "Determinants of Spending by House Challengers, 1974-84". En American Journal of Political Science, Michigan State University, Vol. 31, n³ 3, pp. 457-483.

NAVIA, Patricio y ACEVEDO, Sergio. (2015): “Un método no endógeno para medir el gasto electoral en Chile 2005-2009”. En Revista Mexicana de Ciencias Políticas y sociales, UNAM, vol. 60 n²25, pp. 111-138.

URCULLO, Luis, y MOYA, Emilio. (2009): Control del financiamiento y gasto electoral en Chile (Santiago, Chile Transparente-IDB).

RIVERA, Sebastián. (2012): “Contando pesos. Gastos y votos en las elecciones municipales en Chile 2008". En Revista Búsquedas Políticas, UAH, 2012, Vol. 1, №1. pp. 95-123. 
SALKA William. (2009): "The Determinants of Campaign spending in State Legislative Elections". Midwest Political Science Association Annual Meeting. Chicago, Illinois, April 2-5 2009. Disponible en: http/ / citationallacademic.com// meta/p_mla_apa_research_citation / 3/6/2/ 2/ 9/ pages362297/p362297-35.php

SAMUELS, David. (2001): "Money, elections, and democracy in Brazil". En Latin American Politics and Society, University of Miami, vol. 43, n²2, pp. 27-48. WeINSCHENK, Aaron and HolBROOK, Thomas: (2013): "The Determinants of Campaign Spending in Mayoral Elections".En State and Local Government Review, University of Georgia, March 2014, vol. 46 n 1, pp. 13-27.

\section{LEGISLACIÓN.}

Ley № 19.884 (2015): Sobre Transparencia, Límitey Control del Gasto Electoral. Disponible en: http:/ / www.leychile.cl/ Navegar?idNorma=213283

Ley № 18.700 (2015): Ley Orgánica Constitucional sobre Votaciones Populares y Escrutinios. Disponible en: http:// www.leychile.cl/ Navegar?id Norma=30082 